\title{
Allograft Survival without Immunosuppression in Landrace Pigs after 90 Days
}

\author{
Rafael Valdés-Gonzalez ${ }^{1 *}$, Arturo Mundo Acevedo ${ }^{1}$, Ana L. Rodriguez-Ventura ${ }^{2,3}$, \\ Pedro Valencia Mayoral ${ }^{4}$ \\ ${ }^{1}$ Departamento de Cirugía, Universidad Nacional Autónoma de México, Ciudad de México, México \\ ${ }^{2}$ Hospital Infantil de México, Endocrinología, Mexico, D.F., México \\ ${ }^{3}$ Investigación en Nutrición y Bioprogramación, Instituto Nacional de Perinatología, Mexico, D.F., México \\ ${ }^{4}$ Departamento de Patología, Hospital Infantil de México, Mexico, D.F., México \\ Email: *rvaldes@axacell.com
}

Received August 1, 2013; revised September 1, 2013; accepted September 8, 2013

Copyright @ 2013 Rafael Valdés-Gonzalez et al. This is an open access article distributed under the Creative Commons Attribution License, which permits unrestricted use, distribution, and reproduction in any medium, provided the original work is properly cited.

\begin{abstract}
Allotransplantation is helpful in order to maintain the life in some cases, but immunosuppression causes collateral effects. In this study, we were reporting the results of allografts in Landrace pigs, which were implanted on collagen-generator devices. After 2 weeks of implantation, the devices were carried out to assess allograft viability at 30,60 and 90 days post implant. The implanted cells were islets of Langerhans and the aim was to prove their presence by immunohistochemistry for insulin and glucagon. The results were positive at 30, 60 and 90 days post implant. It demonstrated that the collagen-generator device permits the cell viability without using anti-rejected drugs or immunomodulating cells.
\end{abstract}

Keywords: Allografts; Collagen-Generator Device

\section{Introduction}

Allograft survival has been reported in some patients after kidney, liver and some other allograft without immunosuppression including those with ABO incompatibility and it has been reported as accommodation phenomenon [1]. In a previous study [2], we achieved good results with xenografts of porcine islets and Sertoli cells in humans using the collagen-generator device, and now, we want to test its efficacy without Sertoli cells.

A variety of therapies directed against molecules involved in T-cell activation and function have resulted in long-term islet allograft survival [3,4]. The Edmonton protocol has showed evidence of human islet allograft function, but with the use of strong immunosupression regimens; the islets have been implanted into the liver and these procedures have been reported with some clinical and surgical complications [5].

Xenotransplant of pig pancreatic islets to humans has been reported as an alternative treatment either via the intraportal route or under the kidney capsule with interesting results [6]. In our experience, we used a subcuta-

\footnotetext{
*Corresponding author.
}

neous autologous collagen-generating device for xenograft implants with good results that have been reported elsewhere [2,7].

Allografts were evaluated by using our device. This method is able to preserve the cellular viability without the presence of a chemical immunosuppression or immunomodulating cells.

\section{Methods}

We used six 14-day-old piglets of Landrace race as recipients ( $(n=6)$, and 7 day old piglets $(n=6)$ as donors, from the same breed. The procedure was performed by implanting a device subcutaneously in the abdominal wall of the pig.

All the pigs were treated in a specific pathogen-free environment in accordance with the Association for Assessment and Accreditation of Laboratory Animal Care and local criteria of the Norm of Mexican Sanitary Regulation of the National Ministry of Health of Mexico.

Pancreatectomy and islet isolation were performed following the same technical procedure described elsewhere [2]. Briefly, islets were prepared using Liberase ${ }^{\circledR}$ (Roche) 
digestion. The islet cells were placed in RPMI-1640, 2\% HSA, $0.12 \%$ nicotinamide, and ciproxine $(1.5 \mathrm{mg} / \mathrm{l})$, at room temperature and centrifuged at 1000 r.p.m. for 20 $\mathrm{min}$. The average islet yield was 157,860 IEQs/g of pancreas (S.D.: 36,593), and 290,730 IEQs/pancreas (S.D.: 75,570 ). The purity of the islets was in all cases $85 \%$ as calculated with dithizone staining and viability was $85 \%$ as determined by acridine orange/propidium iodide staining [2]. None of the recipients received immunosuppression at any time.

\section{Results}

Two weeks after implantation of the devices, the transplant procedure was carried out under general anaesthesia by exposing the end of each device, removing the PTFE plunger and infusing into the device a culture solution that contains 125,000 IEQ, which was necessary for the size of the device. The device was then sealed with a small PTFE cap. This approach was proved to be simple and relatively non-invasive, in that it allowed the cells to be transplanted with only a small subcutaneous incision.

The devices were removed after 30, 60 and 90 days of the implant for histology and immunohistochemistry tests for insulin and glucagon because it was easier to demonstrate the viability.

Allograft survival was evident in all the recipients after 30, 60 and 90 days without immunosuppression (Figure 1).

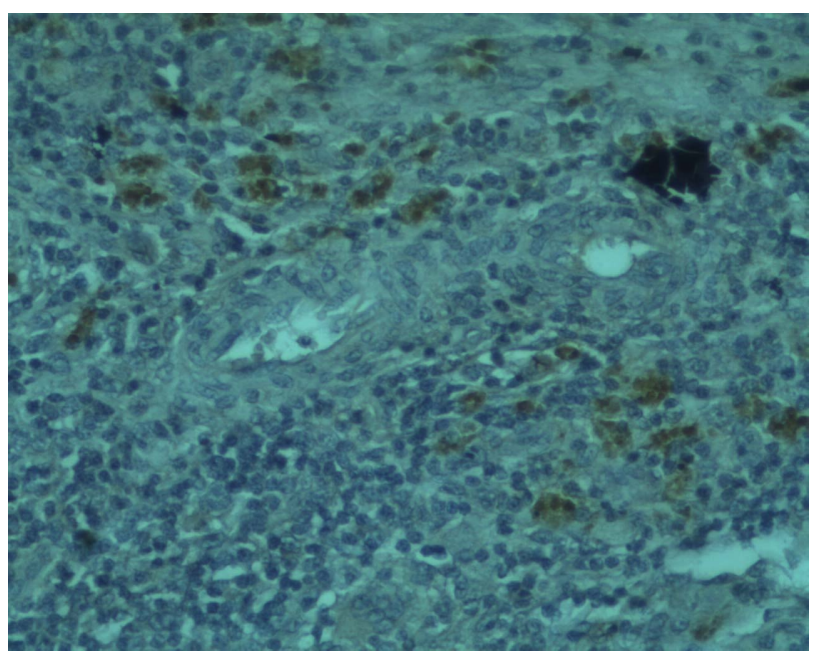

Figure 1. Positive immunohistochemistry for $\beta$ cells (of insulin [B arrow]) and a cells (of glucagon [A arrow]) were found in the animals at 60 days post-transplant.

\section{Conclusion}

The allografts survived for long periods of time without anti-rejection drugs or immunomodulating cells by using this technique and the device. Our results demonstrated that it could be useful to use our device for cellular allograft in humans.

\section{REFERENCES}

[1] K. Takahashi, “A New Immunosuppressive Therapy in ABO Incompatible Kidney Transplantation Based on a New Concept of Accommodation," International Congress Series, Vol. 1292, 2006, pp. 73-87. http://dx.doi.org/10.1016/j.ics.2006.03.054

[2] R. A. Valdes-Gonzalez, L. M. Dorantes, G. N. Garibay, et al., "Xenotransplantation of Porcine Neonatal Islets of Langerhans and Sertoli Cells: A 4-Year Study," European Journal of Endocrinology, Vol. 153, No. 3, 2006, pp. 419-427. http://dx.doi.org/10.1530/eje.1.01982

[3] G. R. Rayat and R. G. Gill, "Indefinite survival of Neonatal Porcine Islet Xenografts by Simultaneous Targeting of LFA-1 and CD154 or CD45RB,” Diabetes, Vol. 54, No. 2, 2005, pp. 443-451. http://dx.doi.org/10.2337/diabetes.54.2.443

[4] D. Y. Lee, S. J. Park, S. Lee, J. H. Nam and Y. Byun, "Highly Poly(Ethylene) Glycolylated Islets Improve LongTerm Islet Allograft Survival without Immunosuppressive Medication,” Tissue Engineering, 2007 [Epub Ahead of Print].

[5] C. N. Street, J. R. T. Lakey, A. M. J. Shapiro, et al., "Islet Graft Assessment in the Edmonton Protocol. Implications for Predicting Long-Term Clinical Outcome,” Diabetes, Vol. 53, No. 12, 2004, pp. 3107-3114. http://dx.doi.org/10.2337/diabetes.53.12.3107

[6] C. G. Groth, O. Korsgren, A. Tibell, J. Tollemar, E. Moller, J. Bolinder, J. Ostman, F. P. Reinholt, C. Hellerstrom and A. Andersson, "Transplantation of Porcine Fetal Pancreas to Diabetic Patients,” The Lancet, Vol. 344, No. 8934, 1994, pp. 1402-1404. http://dx.doi.org/10.1016/S0140-6736(94)90570-3

[7] A. Pileggi, R. D. Molano, C. Ricordi, E. Zahr, J. Collins, R. Valdes and L. Inverardi, "Reversal of Diabetes by Pancreatic Islet Transplantation into a Subcutaneous, Neovascularized Device,” Transplantation, Vol. 81, No. 9, 2006, pp. 1318-1324.

http://dx.doi.org/10.1097/01.tp.0000203858.41105.88 